\title{
Posters can prompt less active people to use the stairs
}

\author{
Jacqueline Kerr, Frank Eves, Douglas Carroll
}

Climbing stairs is an incidental physical activity that people can incorporate within daily life. Observational studies have shown that posters at the point of choice between stairs and escalators can increase stair use..$^{1-3}$ As the greatest public health benefits can be gained from encouraging the least active to exercise more, ${ }^{4}$ stair and escalator users were interviewed to assess whether poster prompts encouraged inactive people to use the stairs.

Participants, methods and results

Interview data from two studies in a Birmingham shopping mall were combined. In each study, a two week baseline period was followed by exposure to a poster, for up to four weeks, which encouraged stair use. The poster was located at the point of choice between the escalators and stairs. Interviews were conducted at the top of the stairwell, between 11 00 am and $1300 \mathrm{pm}$ to include day and lunchtime shoppers, by a pool of five rotating interviewers (inter-interviewer reliability $r=0.76$ ).

To assess physical activity, stage of change for exercise and a modified 14 day physical activity recall were obtained (test re-test reliability $r=0.80$ ). For analysis, each activity was weighted for its intensity (vigorous $=9$; moderate $=5$, light $=3$ ) and then multiplied by the weekly frequency of the activity to give a total activity score. Participants were asked their reasons for using the stairs or escalator and whether they saw the poster. Gender and age were also recorded.

No person was interviewed more than once and the gender of those refusing an interview was noted. A total of 1779 people were approached and 658 provided interviews. Of these, 270 were stair users and 388 escalator users. There were no significant differences in gender, stair use or week of study between interviewees and those who refused.

Logistic regression analyses showed that stair use significantly increased during the intervention periods $(\mathrm{p}<0.00001)$. Analysis of covariance of the total activity scores of interviewees, with age as a covariate, revealed that the activity scores of stair users after the poster intervention were lower than those of stair users during the baseline $(\mathrm{p}=0.02)$. As people with lower customary levels of activity were encouraged to use the stairs by the intervention, the aggregate activity score for stair users was reduced (see fig 1 ). $\chi^{2}$ Analysis of the stage of change data indicated that only $8.6 \%$ of precontemplators reported seeing the poster, compared with $40.1 \%$ of participants in other stages $(p=0.0003)$. The

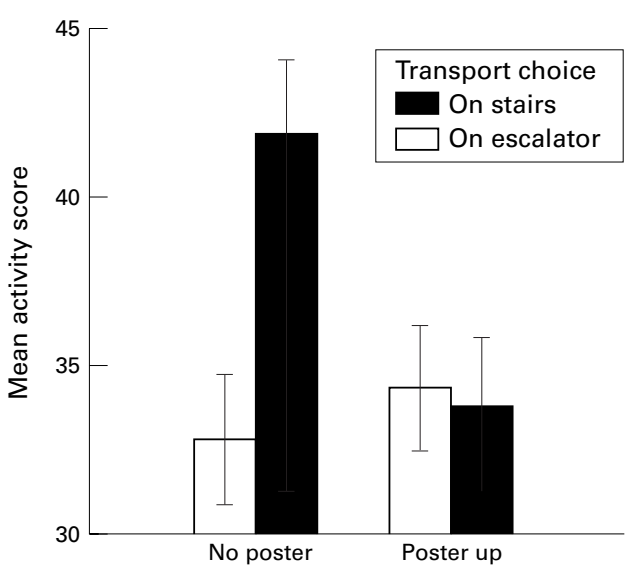

Figure 1 When the poster was in place the mean activity score of stair users decreased, indicating that the poster encouraged those with lower customary levels of activity to use the stairs.

main reason given for stair use was improved health $(41.4 \%)$ whereas ease of use $(30.3 \%)$ and laziness $(24.2 \%)$ were the reasons cited by escalator users.

\section{Comment}

A concern of exercise promoters is that interventions mainly affect those who are already active whereas increasing activity levels in less active people would provide the most benefit for public health. ${ }^{4}$ This study demonstrates that poster prompts can encourage less active shoppers around lunchtime to use the stairs. In the stages of change model, precontemplators, contemplators and preparers are considered insufficiently active. ${ }^{5}$ Although, overall, less active people were encouraged to exercise more by the poster, precontemplators, that is people not considering change, were less likely to see the poster. There is a need to develop strategies that direct precontemplators' attention to environmental cues to exercise. Furthermore, the reasons given for escalator use suggest that messages promoting stair use should tackle motivational barriers to stair climbing. It is conceded that these conclusions should be tempered because a randomised design was not used. The present pre-post design, however, allows for direct comparison with previous studies of stair climbing. ${ }^{1-3}$

We thank Jess Cunliffe, Lianne Evans, Guy Hudson, Claire Pipe, the Health Promotion Department of Greater Glasgow Health Board, and the Pavilions Shopping Centre.

Funding: none.

Conflicts of interest: none. 
1 Brownell KD, Stunkard AJ, Albaum JM. Evaluation and modification of exercise patterns in the natural environmodification of exercise patterns in the

2 Blamey A, Mutrie N, Aitchison T. Health promotion by encouraged use of stairs. BMF 1995;311:289-90.

3 Andersen RE, Franckowiak SC, Snyder J, et al. Can inexpensive signs encourage the use of stairs? Results from a
community intervention. Ann Intern Med 1998;129:363-9.
4 Pate RR, Pratt M, Blair S, et al. Physical activity and public health: a recommendation from the Centers for DiseaseC-
ontrol and Prevention and the American College of Sports Medicine. fAMA 1995;273:402-7.

5 Prochaska J, Marcus B. The transtheoretical model: applications to exercise. In: Dishman R, ed. Advances in exercise adherence. Champaign, IL: Human Kinetics, 1994: 16180. 